\title{
Erratum to: Increased Hippocampal Expression of the Divalent Metal Transporter 1 (DMT1) mRNA Variants 1B and +IRE and DMT1 Protein After NMDA-Receptor Stimulation or Spatial Memory Training
}

\author{
Paola Haeger · Álvaro Álvarez • Nancy Leal · \\ Tatiana Adasme • Marco Tulio Núñez • \\ Cecilia Hidalgo
}

Published online: 23 September 2009

(C) Springer Science+Business Media, LLC 2009

\section{Erratum to: Neurotox Res}

DOI 10.1007/s12640-009-9096-z

There is an error in the caption to Fig. 2. The next-to-last sentence of the caption should read as follows:

We reported the rat sequence from the present work to NIH Genebank (GQ161922).

The online version of the original article can be found under doi:10.1007/s12640-009-9096-z.

P. Haeger $(\varangle)$ · Á. Álvarez · N. Leal · T. Adasme · C. Hidalgo Centro FONDAP de Estudios Moleculares de la Célula, Facultad de Medicina, Universidad de Chile, Independencia 1027,

Santiago, Chile

e-mail: phaeger@med.uchile.cl

\section{T. Núñez}

Departamento de Biología, Facultad de Ciencias and Institute for Cell Dynamics and Biotechnology, Universidad de Chile,

Santiago, Chile

\section{Hidalgo}

Programa de Biología Celular y Molecular, Instituto de Ciencias Biomédicas, Facultad de Medicina, Universidad de Chile,

Santiago, Chile 